\title{
Gene Expression and Function Indry and Fleshy Fruit Development in Solanaceae
}

\author{
Abeer M. Mohamed ${ }^{1}$ and HoussamM. F. Elwakil ${ }^{1,2}$ \\ ${ }^{1}$ Agricultural Botany Dept.,Faculty of Agriculture (Saba Basha), Alexandria University \\ ${ }^{2}$ College of Biotechnology, University of Modern Sciences, Dubai \\ Corresponding author: Abeer M. Mohamed E-mail: abeer.mohamed@gmail.com
}

\begin{abstract}
Fruit development affects fruit quality and quantity.Study of fruit development on the molecular level is very important step toward improvement of fruit production. Setting a comparison between dry- and fleshy-fruit species, across different stages of fruit development, is one way of studying the key factors regulating fruit development. The Solanaceae family found promising in this regard, in which many berry and dry fruit species belong to a common evolutionary history and genetic ancestry; thus theexpression level and role of many similar genes can be compared between two different fruit-type species but arehighly similar in their genetic backgrounds as a member of the solanaceace family.To investigate the molecular processes important in fruit development and differentiation, two model plants were used; tomato (Solanum lycopersicum)and flowering tobacco (Nicotiana sylvestris). In comparison between Tomato and flowering tobacco,this paper study the expression level of ten candidate genes hypothesized to play a role in the development of dry vs fleshy fruits. RT-PCR and qRT-PCR were used to assess expression in different tissues and at different developmental stages.
\end{abstract}

Keywords:fruit development, dry fruit, fleshy fruit, Solanum lycopersicum

\section{INTRODUCTION}

Fruits vary in form and function, but among the most conspicuous and economically important differences are those of the pericarp. In particular, many fruits fall into one of two categories: fleshy indehiscent (e.g., berries, in which the pericarp layers proliferate) or dry dehiscent (e.g., capsules, in which the pericarp becomes lignified). Comparative molecular studies in closely related species allow us to identify the genetic mechanisms underlying fruit development such as differentiation of a fleshy versus a dry pericarp.

Molecular mechanisms of fruit development have been characterized inArabidopsis thaliana (Brassicaceae)(Gu et al., 1998; Ferrándiz et al., 2000; Dinneny et al., 2005; Fuentes et al., 2012). However, Brassicaceae are not suited to a comparative study as the family is characterized by a single dry dehiscent fruit type (silique)(Cronquist, 1981). A more amenable framework for comparative study of dry vs. fleshy fruit is provided by the Solanaceae family. Solanaceae included many berry fruit type(e.g. Tomato and eggplant) and many dry fruits (e.g. Nicotiana). Despite having different forms of fruit, Solanaceae family have a common evolutionary history and genetic ancestry; thus the roles of orthologous genes can be compared in genetic backgrounds that are highly similar (Wang et al., 2015). 
Fruit development has been studied in tomatoand the process has been divided into four stages (Tanksley, 2004; Carrari and Fernie, 2006): (1) ovary development prior to fertilization of the ovules, (2) a period of cell division triggered by fertilization, (3) the cessation of cell division and the onset of cell expansion, and (4) ripening. A comparative anatomical study done byPabón-Mora and Litt (2011) showed the four corresponding stages can be identified in the development of capsules: (1) ovary development; (2) onset of cell division; (3) cessation of cell division accompanied by lignification; and (4) final maturation.

Although Most analyses of fruit development in tomato have focused on molecular changes occurred during stage 4 (ripening) (Barry et al., 2005; Giovannoni, 2007; Chen et al., 2015), the changes that are responsible for the dramatic differences in structure between capsules and berries initiated at stage 2 (Pabón-Mora and Litt2011). Few studies have shown that genes acting prior to fertilization (during stage 1) influence fruit shape and size (Xiao et al., 2009), and that fertilization (stage 2) triggers many ripening-related transcriptional changes in the pericarp (Gillaspyet al., 1993; Xiao et al., 2009).

This study uses a comparative approach to identify differences in expression level of some genes that may play role in capsule and berry development in Solanaceae. Due to their numerous genetics resources available,dry fruit species (Nicotiana sylvestris Speg. (Flowering tobacco), and fleshy fruit species (Solanum lycopersicum L. cv.Micro-Tom (tomato) were used. We performed reverse transcription- polymerase chain reaction(RT-PCR) to compare expression of 10 genes in various organs and during vegetative and fruit development in both species. Quantitative (qRT-PCR) were further used to study 6 genes out of 10 to look in depth at their level of expression during the 4 stages of fruit development to identify candidate genes for further functional studies

\section{MATERIALS AND METHODS}

\section{Tissue collection:}

For all experiments, five plants each of $S$. lycopersicum cv. MicroTom(tomato) and $N$. sylvestris (flowering tobacco) were grown under growth conditions of $22^{\circ} \mathrm{C}$, and 12 hours light.For qRT-PCR, ovaries/fruits from both Tomato and Nicotiana were collected at different stages of fruit development as characterized by Pabón-Mora and Litt2011. In Tomato; stage 1(anthesis; once flower open), stage 2 (2 days post-anthesis; T2),Stage 3(13-days post-anthesis; T13) and stage 4(breaker fruit stage; TBR). On the other hand,in Nicotiana; stage 1(at anthesis; once flower open), stage2 (4-days post-anthesis; N4), stage 3 (7days postanthesis; N7) and stage 4 (18-days post-anthesis; N18). For RT-PCR, tissue were collected from stem, leaf, young bud, and bud pre-anthesis.All tissue samples were collected from three biological replicates and stored at $-80^{\circ} \mathrm{C}$. 


\section{In situ hybridization:}

Flowering tobacco fruits at anthesis and 1-6 days post-anthesis (DPA) were collected and fixed for four hours under vacuum on ice in freshly prepared FAA (50\% ethanol, $3.7 \%$ formaldehyde and 5\% glacial acetic acid). Samples were subsequently prepared for sectioningat $10 \mu \mathrm{m}$ with a steel blade. For probe synthesis, RNA from bud were used for cDNA synthesis as below. For the antisense probe, a $300 \mathrm{bp}$ fragment of histone $\mathrm{H} 4$ was amplified using Forward primer a reverse primer carrying a $\mathrm{T} 7$ promoter sequence $(\mathrm{H} 4 \mathrm{~F}$ : GTCTGGTCGTGGAAAGGGAGGCAAGGG; $\quad \mathrm{H} 4 \quad \mathrm{R} \quad \mathrm{T7}$ : CTTAATACGACTCACTATAGGGTTAACCGCCAAATCCATACAGAGTCC). For a sense probe, the T7 promoter sequence added on the forward primer $(\mathrm{H} 4 \mathrm{~F}$ T7: CTTAATACGACTCACTATAGGGGTCTGGTCGTGGAAAGGGAGGCAAGGG; $\mathrm{H} 4 \mathrm{R}$ : TTAACCGCCAAATCCATACAGAGTCC). Amplified products were used to synthesize Digoxigenin (DIG)-labeled RNA probes with T7 polymerase (Roche Applied Science),RNA in situ hybridization was performed according to De Martino et al.(2006), with an overnight hybridization at $52^{\circ} \mathrm{C}$.Images of the slides recorded using a microscope-mounted Nikon DXN1200c digital camera.

\section{Reverse transcription PCR (RT-PCR) expression analyses:}

Total RNA was prepared from approximately $100 \mathrm{mg}$ of each of the 11 tissue types collected from each species using the Trizol reagent (Invitrogen). After DNAse treatment,Total RNA was reverse transcribed using $1.5 \mu \mathrm{g}$ of RNA with random hexamers and the High Capacity cDNA Reverse Transcription Kit (Applied Biosystems). To evaluate expression levels, cDNA template was diluted to a standard concentration $20 \mathrm{ng} / \mu \mathrm{L}$. 18S was used as a control. PCR was performed in $25 \mu \mathrm{L}$ reactions containing $12.5 \mu \mathrm{L}$ of PCR mix, 5 nmoles of each primer, and $20 \mathrm{ng}$ of cDNA. Cycling parameters start with 1 cycle at $94^{\circ} \mathrm{C}$ for 5 minutes, 30 cycles at $94^{\circ} \mathrm{C}$ for $30 \mathrm{~s},[\mathrm{Ta}]^{\circ} \mathrm{C}$ for $30 \mathrm{~s}, 72^{\circ} \mathrm{C}$ for $30 \mathrm{~s}$ followed by final extension step at $72^{\circ} \mathrm{C}$ for $5 \mathrm{~min}$.

\section{Quantitative Real-Time RT-PCR (qRT-PCR):}

The selected genes were evaluated using qRT-PCR at the four stages of fruit development. Total RNA from stages 1, 2, 3, and 4 fruits collected from three plants per species was prepared using the RNAqueous Kit (Ambion) according to manufacturer's protocols. The cDNA for qRT-PCR was prepared using $2.0 \mu \mathrm{g}$ of total RNA per sample, the Superscript III First Strand Synthesis System (Invitrogen), and random hexamers. In nuclease -free reaction volume of $25 \mu \mathrm{L}, 10$ ng of cDNA template was mixed with $12.5 \mu \mathrm{L}$ of $2 x$ FastStart SYBR Green PCR Mastermix (Applied Biosystems), 250uM of forward and reverse primers. Relative quantification(RQ) values were used as standardized expression values and expression ratios were generated by dividing each flowering tobacco $R Q$ value by the $R Q$ value of the tomato ortholog. For each gene and tissue, the three 
biological replicates, each with three technical replicates, were evaluated. Elongation factor 1 alpha(EF1a) genewas used as a reference gene for all samples.

To design primers, candidate gene contigs were aligned with close BLAST hits of SGN unigene sequences. These alignments were used for designing genespecific primers using the Primer Express software (Applied Biosystems). Primer sequences shown in table 2Thermocycling was performed on an ABI-PRISM 7300 Real-Time PCR system (Applied Biosystems) using the default conditions of 2 min at $50^{\circ} \mathrm{C}, 10 \mathrm{~min}$ at $95^{\circ} \mathrm{C}$, and 40 cycles of the following: $15 \mathrm{sec}$ at $95^{\circ} \mathrm{C}$ and $1 \mathrm{~min}$ at $60^{\circ} \mathrm{C}$. Relative quantification $\left(\log _{10} R Q\right)$ values were plotted and the lowest gene expression value from all replicates was calibrated to 0 to eliminate negative values. Analysis of Variance (ANOVA) and Tukey-Kramer tests were performed in Excel 2007 to test for significant differences in expression.

\section{RESULTS AND DISCUSSION}

During stage two, the anatomical and morphological differences that distinguish berries from capsules become manifest (Pabón-Mora and Litt, 2011). This stage, which marks the onset of fruit development per se, is initiated at 2 DPA in tomato (Gillaspy etal., 1993), and consistent with the onset of rapid and prolific cell division in the pericarp and so rapid growth in fruit size (Bertin et al., 2003). Flowering tobacco capsules undergo a similar (albeit lesser) increase in size starting at 4 DPA; this delay in the onset of growth relative to tomato may be due to the larger style and thus much larger distance the pollen tube must cover to reach the ovules. Testing the expression of histone $\mathrm{H} 4$, as a markerof active cell division (Schantzet al., 2001), show that stage 2, onset of cell division, initiated at 4DPA of tobacco capsule development (Fig.1).

\section{Selection of candidate genes for additional analyses:}

Literature searches and results fromTOM2 microarray, 70-mer oligo array with 1200 unigenes represented (data not shown)were used to select 10 candidate geneson the basis of differential expression at stage 2 ( $>2$-fold difference in expression). We focused on transcription factors and genes with predicted functions related to fruit development processes such as cell division and lignification. A putative assessment of orthology was made based on BLAST searches of GenBank and Sol Genomics Network (SGN). We named genes as follows: (1) if published names were available for both or either species, those names were used (e.g., SIFUL2, NsMADS1,SIETR4); (2) if neither species had a published name, we used the name of the top BLAST hit, adding the prefixes "Sl" or "Ns" (e.g.,SIUGD,NsUGD). Table 1 is showing Gene names and abbreviations, SGN unigene numbers andGenBank ID. 


\section{RT-PCR expression analyses:}

The expression patterns of the 10 candidate genes were evaluated in 11 tissues including vegetative tissues, early, and preanthesis buds, all floral organs (sepal, petal, stamen and carpel) at stage1, and fruits at stages 2, 3, and 4. Results are shown in Fig.2.All genes were expressed in leaves,preanthesis buds, carpels and fruits at stages 1,2, and 3 except NsEXT-LIKE and NsDWF1. The gene expression in both vegetative and reproductive tissues support the notion that most genes involved in fruit development are not specific to those processes but also function in other aspects of plant growth and development.

Expression of NsDWF1, NsETR4, NsFW2.2, NsDDTFR18 and NsPalwas seen in stems and leaves. As with tomato, expression in floral organs was variable, in some cases reduced or absent in sepals (NsEXT-LIKE, NsMADS1, $N s U G D$ ), or, in the case of NsFW2.2, absent from all floral organs except the carpel. All genes were expressed in stage 1 carpels. Expression of NsDWF1 was not seen at later stages of fruit development. Expression of NsETR4 tapered off during fruit development but expression of NsMADS1, NsMADS3, NsPGIP, and NsUGD appeared to remain constant.

As has been shown in RT-PCR, the genes SIPAL3/NsPAL3, SLDDTFR19/NsDDTFR19, and SIH2A-LIKE/NsH2A-LIKE were expressed constantly and at similar levels in all tissues in both species.Considering the high probability of their pleiotropic functions; those three genes were excluded from further analysis.SIPAL3 has been shown to be expressed in all organs of the tomato plant (Lee et al., 1992); our results suggest that expression is also consistent throughout carpel and fruit development. PAL catalyzes the first step in the phenylpropanoid pathway, from which lignin is synthesized (Ro and Douglas, 2004); as lignification is one of the fundamental processes that distinguishes dry and fleshy fruits, this seemed a potentially informative candidate. However, this pathway yields many other metabolites found in a variety of tissues. H2A-LIKE protein may play a role in chromatin structure and nucleosome assembly, and is linked to stress-response and hormone factors (Clemens and Hake, 2012). Although the microarray results (data not shown) show this gene to be expressed at much higher levels in flowering tobacco, RT-PCR analysis suggests it does not show any tissue specificity.

SIEXT-LIKE/NsEXT-LIKE were not included in further analyses because preliminary qRT-PCR experiments produced inconsistent results that suggested the possibility of more than one amplification product. Although little is known about the gene SIEXT-LIKE/NsEXT-LIKE, it may be involved in cell wall extensibility similar to other extensin proteins (Kieliszewski and Lamport, 1994). 
J. Adv. Agric. Res. (Fac. Agric. Saba Basha)

\section{qRT-PCR expression analyses:}

We performed qRT-PCR on 6 genes(SIDWF1/NsDWF1, SIETR4/NsETR4, SIFW2.2/NsFW2.2, SIFUL2/NsMADS1, SIMADS1/NsMADS3, and SIUGD/NsUGD) that exhibited dynamic expression patterns in the RT-PCR expression analysis. QRT-PCR analyses were performed across all four stages of fruit development in both species. This allowed us to evaluate differences in expression over the course of fruit development as well as between the two species.

Results in Fig. 3 showed the averaged log-transformed relative transcript quantities (RQ). We performed an ANOVA to test for significant differences in gene expression among all 8 tissues (2 species, 4 developmental time points). Significant differences were found between tissues for each gene $(P<0.05)$, we performed a Tukey-Kramer test to look for significant differences among fruit development stages within each species, and between equivalent stages in the two species (Fig. 3). In tomato, SIMADS1, FW2.2, and SIDWF1, were shown to be differentially expressed across developmental stages. SIMADS1 showed differences among all stages, with expression increasing to stage 3 and then declining dramatically. FW2.2 expression was significantly different only between stages 1 and 2, showing a strong increase at the onset of cell division. SIDWF1 was significantly different between stages 2 and 4, with a sharp drop at ripening. In flowering tobacco, NsDWF1 and NsMADS3 expression did not vary significantly but NsETR4, NsMADS1, NsFW2.2, and NsUGD were all differentially expressed. NsFW2.2, andNsMADS1 showed a highly dynamic pattern across all four stages. NsETR4 showed a significant increase at stage 4, and NsUGD showed a significant decrease from stage 2to 3 followed by an increase to ripening at stage 4 .

Tests comparing equivalent stages in the two species showed that four of the 6 genes, SIDWF1/NsDWF1SI, SFW2.2/NsFW2.2, MADS1/NsMADS3, andSIUGD/NsUGD, showed significantly different expression at stage 2.SIUGD/NsUGD showed consistently higher expression in flowering tobacco compared to its lower expression in tomato. SIDWF1/NsDWF1 and SIFW2.2/NsFW2.2 were differentially expressed at all but stage 4 (ripening); SIDWF1 expression was barely detectable in flowering tobacco whereas its ortholog was consistently fairly strong in tomato. Expression of SIMADS1/NsMADS3 was significantly different at all stages except stage 3, whereas, both SIETR4/NsETR4 and SIFUL2/NsMADS1 were only differentially expressed in stage 3.

Comparison of the dynamics of expression of these 6 genes shows that in tomato, expression of a number of genes tapered off as development progressed, with a peak in expression at stage 2; this pattern is seen in all of the genes analyzed except SIETR4 and SIFUL2)(Fig 3). This decline in expression at stage 4 suggests that downregulation of these genes may be required to promote the processes of ripening such as cell wall softening. Conversely, in flowering 
tobacco, expression was strongest at stages 2 and 4 for all genes exceptNsDWF1. This suggests that these genes may play an important role in capsule maturation processes.

\section{Candidate gene expression and putative function in dry and fleshy fruit development SIDWF1/NsDWF1:}

The Arabidopsis DWARF1 gene encodes a membrane-bound protein involved in brassinosteroid synthesis (Klahreet al., 1998). Brassinosteroid-deficient plant Mutants in Arabidopsis and Tomato are severely dwarfed and have reduced fertility in Arabidopsis and delayed fruit ripening in Tomato (Vardhini and Rao, 2002; Symons et al., 2006; Fu et al., 2008).The brassinosteroid-deficient "rinrei" mutant of faba bean (Viciafaba) produces short seed pods (Fukutaet al., 2004).Our results (Fig.3) indicate that NsDWF1 is not expressed in flowering tobacco fruit tissue after fertilization, stage 3 and 4, whereas SIDWF1 is expressed throughout all four stages of fruit development, although expression decreases at stage 4. Flowering tobacco capsules cease growth shortly after the onset of stage 2, whereas tomato fruits continue to grow until stage 4; this duration of growth is correlated with the expression of NsDWF1 and SIDWF1, and is consistent with the hypothesis that these genes regulate brassinosteroid synthesis and thereby regulate growth processes.

\section{FW2.2/NsFW2.2:}

FW2.2 activity during early carpel development has been shown tocontrols up to $30 \%$ of fruit weight variation and was the first gene underlying a quantitative trait locus (QTL) that was identified by a positional cloning approach (Fraryet al., 2000;Nesbittet al., 2001 ). Our analyses indicate that there were significant differences in expression at equivalent developmental stages (stages 1-3) in tomato and flowering tobacco, as well as significant differences among some stages within each species (Fig.3). Expression, particularly in flowering tobacco, appears dynamic; in this species it decreases sharply from stage 2 to 3 and then increases again. This pattern is not consistent with cell division activity in capsule formation (or seed development), suggesting either a different role for this gene or the involvement of other factors in regulating cell division.

\section{SIFUL2/NsMADS1:}

SIFUL2 (also referred to as SIMBP7; Hilemanet al., 2006) is a member of the AP1/FUL MADS-box transcription factors. The Arabidopsisortholog FRUITFULL (FUL) is required for proper cell differentiation in the silique valves and repression at the valve margins is required for proper lignification of the dehiscence zone (Gu et al., 1998; Ferrándiz et al., 2000; Smykalet al., 2007). In general the role of FUL genes in fleshy fruit development is unknown, although downregulation of VmTDR4 in bilberries suggests a role in anthocyanin accumulation (Jaakola, 2010). Studies have identified four FUL orthologs in tomato, all but one 
expressed in fruit (Busiet al., 2003; Hilemanet al., 2006). In our analysis one of these, SIFUL2, is expressed constantly throughout fruit development (Fig.3). In contrast, expression of the flowering tobacco ortholog, NsMADS1, is highly dynamic over the four developmental stages (Fig. 3). Expression is lowest at stage 3 , correlated with the onset of lignification; however, it increases at stage 4 when the capsule undergoes drying and dehiscence. The difference in expression patterns suggests a role in processes that differentiate dry and fleshy fruit development.

\section{SIMADS1/NsMADS3:}

SIMADS1 is a MADS-box transcription factor belonging to the SEPALLATA (SEP) lineage (Hilemanet al., 2006). They found to be required for proper floral organ identity (Pelaz et al., 2000; Prasad et al., 2005).Tomato SEP homologs, TM5 and TM29, repress fruit development in the absence of fertilization (AmpomahDwamena et al., 2002). Leseberget al. (2008) found SIMADS1 protein interacts with TM4, a tomato ortholog of Arabidopsis FUL, suggesting a possible role for SIMADS1 in fruit development. Hileman et al. (2006) showed expression during all stages of fruit development with a steep drop at the final stage. Our results confirm these data (Figs. 2, 3) including the sharp decrease in transcript quantity at stage 4 (Fig. 3). In contrast, expression of the flowering tobacco ortholog, NsMADS3, is maintained at a relatively high level throughout capsule development. Jang et al.(1999) and Dong et al.(2007) have suggested that Solanaceae SEP orthologs function in regulating flowering time and apical dominance, but not during fruit development. The higher and consistent levels of expression in flowering tobacco relative to tomato (Fig. 3) suggest that this transcription factor may play a role in differentiating dry fruit types.

\section{SIUGD/NsUGD:}

UDP-glucose dehydrogenases play a key role in the synthesis of hemicelluloses, important fiber components of plant cell walls. This function is suggested from the high expression of tobacco( $N$. tabacum) NtUDPGDH1 and2 (paralogs that are putative orthologs of SIUGD/NSUGD) in tissues undergoing synthesis of secondary cell walls (Bindschedleret al., 2005). In our analyses, expression of NsUGD was high throughout fruit development (Fig.3), which is correlated with observation of enhanced secondary cell wall formation in 4 DPA flowering tobacco fruits (Pabón-Mora and Litt, 2011). In contrast, expression of the tomato orthologs, SIUGD, was consistently low at all four stages. This is consistent with a role for UDP-glucose dehydrogenase in secondary cell wall synthesis, a more prominent process in capsule than berry development, although the reason for high levels of this transcript in flowering tobacco prior to anthesis, when there is little secondary cell wall formation, remains unclear. In addition, hemicelluloses are important components of all plant cell walls; thus, future functional analyses are needed to clarify the role of this gene in fruit development. 


\section{SIETR4/NsETR4:}

Ethylene receptor 4 is a negative regulator of ripening as with its downregulation in tomato lead to accelerated fruit ripening (Klee, 2002 ;Kevanyet al., 2008). Silique development in Arabidopsis is not sensitive to ethylene (Ferrándiz, 2002); however, ethylene insensitive transgenic petunia lines showed delayed capsule maturation (Shibuya et al., 2004). This suggests a role in fruit maturation in dry-fruited as well as fleshy-fruited Solanaceae. SIETR4 is not expressed significantly differently among the four stages of fruit development in tomato (Fig.3), which is in contrast to expectations that it should be downregulated at stage 4 (ripening), but consistent with findings in other studies (Kevanyet al., 2008). Expression of the ortholog in flowering tobacco, NsETR4, is similar to tomato with the exception of stage 3 , at which is significantly downregulated (Fig.3).

Table (1): Candidate genes chosen for expression analyses.

\begin{tabular}{|c|c|c|c|}
\hline $\begin{array}{c}\text { Closest BLAST hit } \\
\text { (species, Gen Bank accession number) }\end{array}$ & $\begin{array}{l}\text { Abbreviation } \\
\text { in tomato } \\
\text { Solanum } \\
\text { lycopersicum }\end{array}$ & $\begin{array}{l}\text { Abbreviation } \\
\text { in flowering } \\
\text { tobacco(Nicoti } \\
\text { ana sylvestris) }\end{array}$ & $\begin{array}{l}\text { ID (SGN } \\
\text { Unigene or } \\
\text { GenBank) }\end{array}$ \\
\hline $\begin{array}{l}\text { MADS-BOX PROTEIN } 1 \text { (S. lycopersicum AY294329) } \\
\text { MADS-BOX PROTEIN } 3 \text { (N. sylvestris AAD39034) }\end{array}$ & SIMADS1 & NsMADS3 & U591985 \\
\hline $\begin{array}{l}\text { FRUITFULL-like MADS-box (S. lycopersicum } \\
\text { AY306156) MADS-BOX PROTEIN II (N. sylvestris } \\
\text { AF385746.1) }\end{array}$ & SIFUL2 & NsMADSII & U580493 \\
\hline $\begin{array}{l}\text { EXTENSIN-LIKE PROTEIN (S. lycopersicum } \\
\text { AAT90376) }\end{array}$ & SIEXT-LIKE & NsEXT-LIKE ${ }^{\mathrm{a}}$ & U222471 \\
\hline DWARF1/DIMINUTO (S. Iycopersicum AAT90376) & SIDWF1 & $N s D W F 1^{\mathrm{a}}$ & U213594 \\
\hline $\begin{array}{l}\text { UDP-GLUCOSE DEHYDROGENASE } \\
\text { (Gossypiumhirsutum, GQ292787) }\end{array}$ & SIUGD ${ }^{a}$ & $N s U G D^{\mathrm{a}}$ & U221859 \\
\hline $\begin{array}{l}\text { histone 2A-LIKE PROTEIN (Solanum melongena } \\
\text { BAA85117) }\end{array}$ & $S I H 2 A-L I K E^{a}$ & $N s H 2 A-L I K E^{a}$ & U214809 \\
\hline $\begin{array}{l}\text { RIPENING-REGULATED PROTEIN DDTFR19 (S. } \\
\text { lycopersicum AAG49033) }\end{array}$ & SIDDTFR19 & NsDDTFR $19^{\mathrm{a}}$ & U578260 \\
\hline $\begin{array}{l}\text { PHENYLALANINE AMMONIA LYASE } 3 \text { (S. } \\
\text { lycopersicum } \mathrm{M} 83314^{\mathrm{b}} \text { ) }\end{array}$ & SIPAL3 & $N s P A L 3^{\mathrm{a}}$ & M83314.1 $1^{b}$ \\
\hline FRUIT WEIGHT 2.2 (S. lycopersicum AF411809) & SIFW2.2 & $N s F W 2.2^{\mathrm{a}}$ & AF411809 \\
\hline Ethylene receptor 4 (S. lycopersicum AY600438) & SIETR4 & NsETR4 $4^{\mathrm{a}}$ & $\mathrm{N} / \mathrm{A}$ \\
\hline
\end{tabular}

${ }^{*}$ Column 1: the BLAST hit used to name the gene, the species from which it was derived, and the GenBank accession number. Column 2 and 3: abbreviations used in tomato and flowering tobacco. ID refers to the unigene identifier specific for the microarray probe for that gene was generated. ${ }^{\mathrm{a}}$ Name assigned in this paper. ${ }^{b}$ GenBank ID M83314.1 corresponds to an unpublished PAL gene determined to be SIPAL3 based on comparison with sequences published in Lee et al. (1992). 


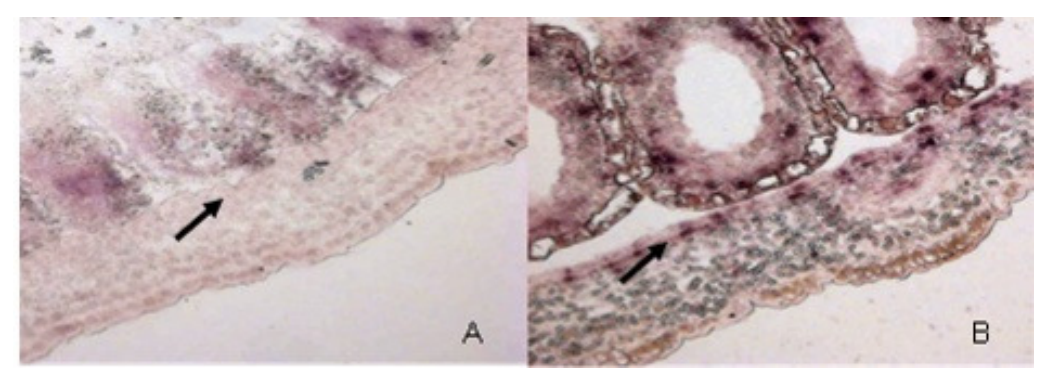

Figure (1): Cell division in flowering tobaccocapsule development. Histone $\mathrm{H} 4$ in situmRNA hybridization. (A) Transverse section of the ovary at anthesis showing segment of the ovary wall and ovules. Stainingis absent in the ovary wall including inner layers(arrow). (B) Transverse section of the developing fruit at four days postanthesis showing segment of the pericarp and developing seeds. Stainingis present in the inner layers of the pericarp(arrow), indicating active cell division. Celldivision occurs in ovules and seeds throughout ovary andfruit development.

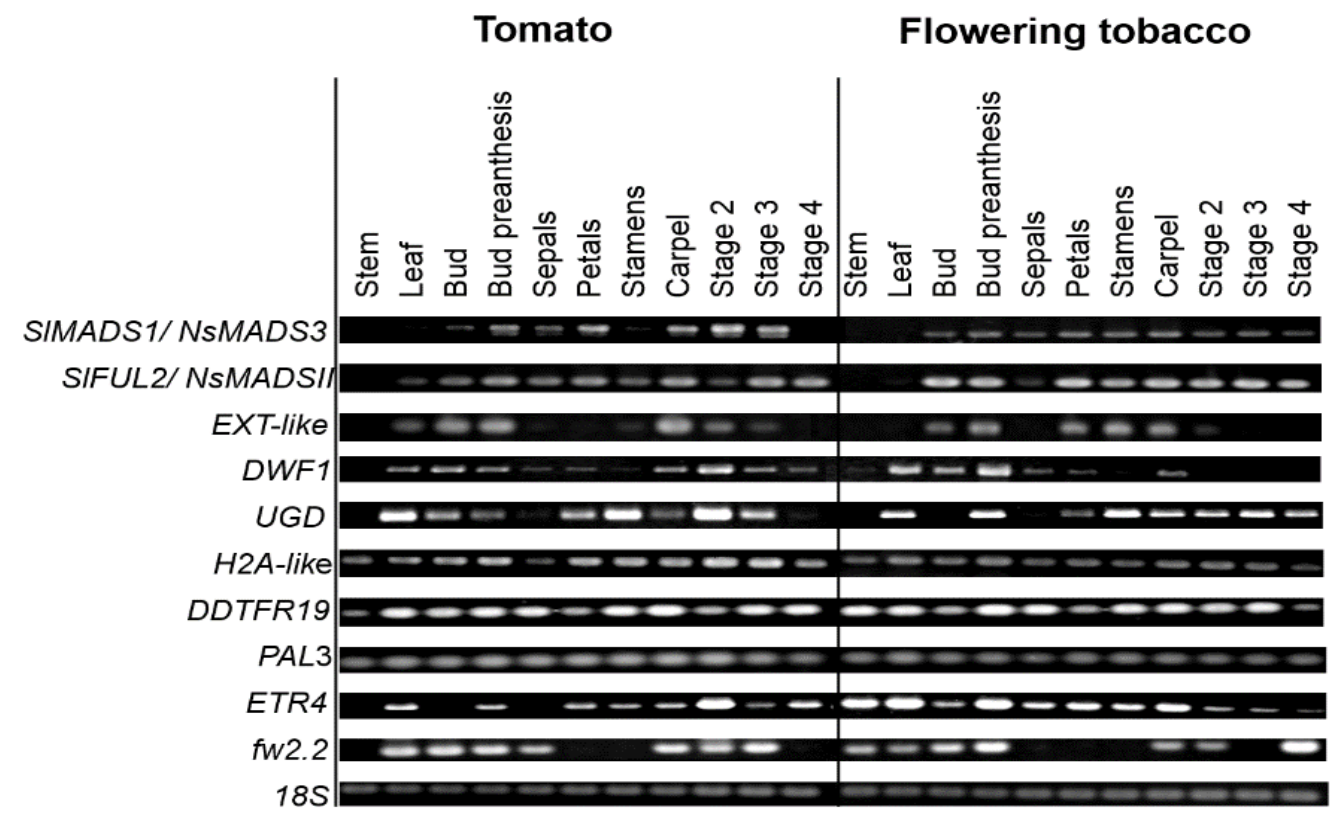


Figure (2): RT-PCR expression profiles for 10 candidate genes in tomato and flowering tobacco tissues. $18 \mathrm{~S}$ was used as loading control. Stem and leaf of vegetative tissue, Bud, bud preanthesis, Sepals, petals, Stamen, and carpel at anthesis (stage 1); stages 2-4 of fruit development.
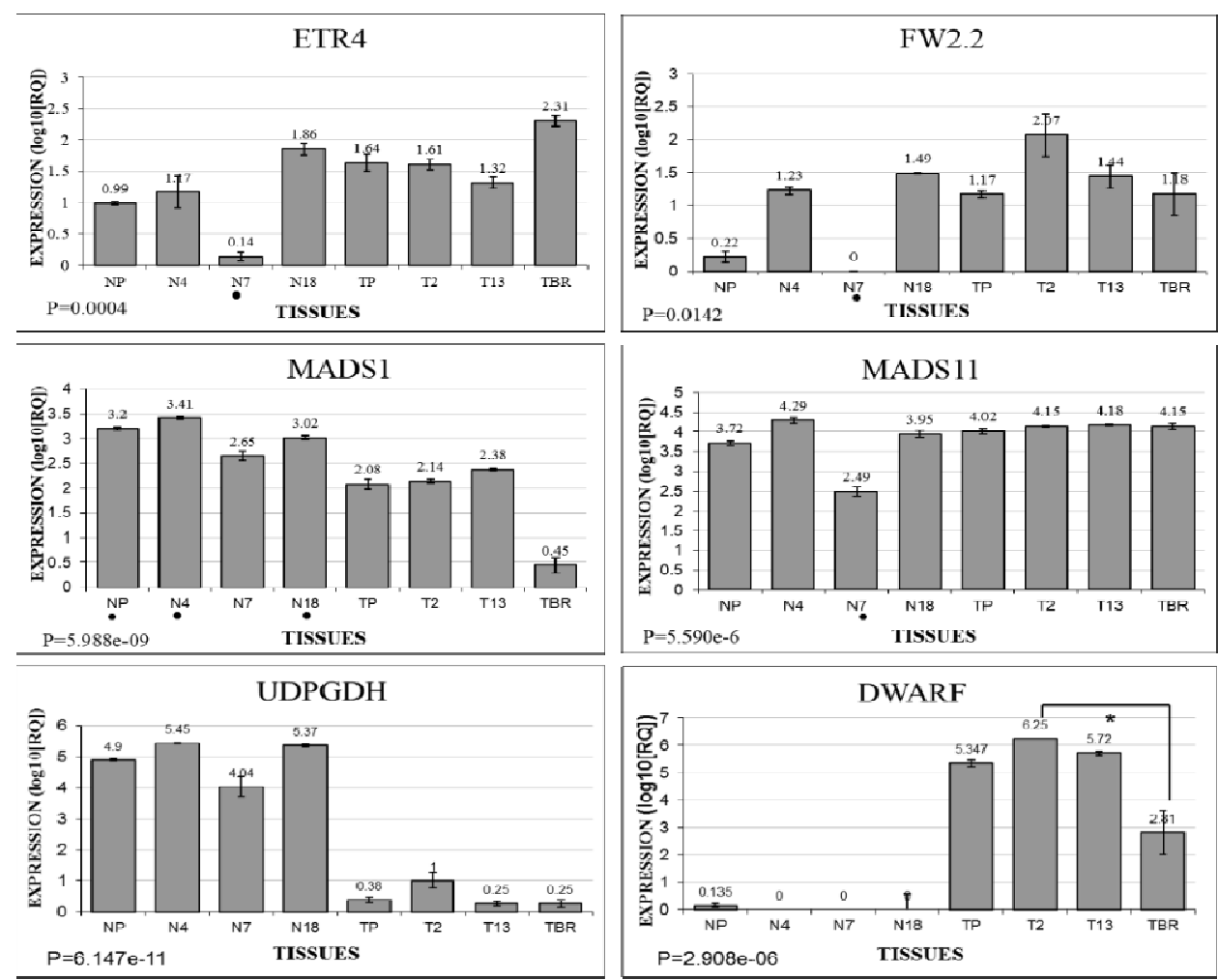

Figure (3): Quantitative RT-PCR results showing gene expression across four fruit development stages in tomato (preanthesis; TP, 2-days; T2, 13-days; T13, and breaker; TBR) and Nicotiana (preanthesis; NP, 4-days post anthesis; N4, 7-days postanthesis; N7, and 18-days post anthesis; N18). Six genes were analyzed with three biological replicates and three technical replicates. Numbers above bars are relative expression values. Error bars represent standard errors. Analysis of variance $P$ values are shown. *, expression levels differed significantly between two stages within a species; $\cdot$, significant differences between corresponding stages in flowering tobacco and tomato (Tukey Kramer test). 
Table (2): List of primers used for RT-PCR and qRT-PCR analysis

\begin{tabular}{|c|c|}
\hline genes amplified & Primers sequences \\
\hline SIMADS1 and NsMADS3 & $\begin{array}{l}\text { F:5'TCAACTCGGACTCAGTTAATGTTGGATCAACTTA3' } \\
\text { R: 5' GTTTGAGTTGTTTGCCGGCCATAGCCCA 3' }\end{array}$ \\
\hline SIFUL2 and NsMADSII & $\begin{array}{l}\text { F: 5' CAAAAGAAGGACAAGGCATTGCAAGA 3' } \\
\text { R: 5' GTGGGAGCAACAGAGCCATGATCATCT 3' }\end{array}$ \\
\hline $\begin{array}{l}\text { SIEXT-LIKE and NsEXT- } \\
\text { LIKE }\end{array}$ & $\begin{array}{l}\text { F: 5' TACTTATTGTGATATCGATAGCCCTTGT3' } \\
\text { R: 5' CCAACATTACACTTAATTAGTGTAC3' }\end{array}$ \\
\hline $\begin{array}{l}\text { SIDWF1 } \\
\text { NsDWF1 }\end{array}$ & $\begin{array}{l}\text { F: 5'GACGGAGAAGAACTTCTGGAGAAT 3' } \\
\text { R: 5'CTCTTGCTCAGCTTCCTGCACCTCCT 3' } \\
\text { F: 5' GGACCTATTTTGAGGGGTGAGGTCT 3' } \\
\text { R: 5' GATGGCTCTATACTTTTTCCTGCAGT3' }\end{array}$ \\
\hline $\begin{array}{l}\text { SIUGD } \\
\text { NsUGD }\end{array}$ & $\begin{array}{l}\text { F: 5' TCGCATCACAGCCTGGAA 3' } \\
\text { R: 5' TCGAGGCCTGGCTCATAGAT 3' } \\
\text { F: 5'GGATGCTTATGCAGCCACAA 3' } \\
\text { R: 5' ACTCATCCCACTCGGTCAAAA 3' }\end{array}$ \\
\hline $\begin{array}{l}\text { SIH2A-LIKE } \\
\text { NsH2A-LIKE } \\
\text { Both }\end{array}$ & $\begin{array}{l}\text { F: 5’ TGCTTTTGGCTGTGAGGAATGATGAA 3' } \\
\text { F: 5' ATGGTGGTGTTCTTCCAAACATC 3' } \\
\text { R: 5' GGAGATTTG GTAGCTTTGGA 3' }\end{array}$ \\
\hline $\begin{array}{l}\text { SIDDTFR19 } \\
\text { NsDDTFR19 }\end{array}$ & $\begin{array}{l}\text { F: 5'CGAAGAATCACACAGCCCATAA 3' } \\
\text { R: 5'TGGGTTTCTTGATTCCATTCCT 3' } \\
\text { F: 5' CTCTGGTTCCGCAAGAACTTG 3' } \\
\text { R: 5'CCCAGGAAACACCGTCACA 3' }\end{array}$ \\
\hline $\begin{array}{l}\text { SIPAL3 } \\
\text { NsPAL3 } \\
\text { Both }\end{array}$ & $\begin{array}{l}\text { F: 5'CCAGAACCAACTGCTGTGCCATT 3' } \\
\text { F: 5'CCAGAACCAACTGCAGTACCATT 3' } \\
\text { R: 5' TTTTCGAGTTGCAGCCTAAGG 3' }\end{array}$ \\
\hline SIETR4 and NsETR4 & $\begin{array}{l}\text { F: 5'TCAGCTACATTCCATGATAAAAGAAGCTGC 3' } \\
\text { R: 5'GAGTTTTTCAAGTTATTCTTCATATGGTTGG 3' }\end{array}$ \\
\hline $\begin{array}{l}\text { SIFW2.2 } \\
\text { NsFW2.2 }\end{array}$ & $\begin{array}{l}\text { F: 5' GTGAAGATAAGTTTGATTAAAGTTGTTAT 3' } \\
\text { R: 5' ATTTAGCTGCAGGAAACTAATCCA 3' } \\
\text { F: 5' TATGTATAAGGTGTTATTTAATTT 3' } \\
\text { R: 5' ATAATTACCCCAATAATCGTAAGAT 3' }\end{array}$ \\
\hline$E F L \alpha$ & $\begin{array}{l}\text { F: 5' ATTGGAAACGGATATGCTCCA 3' } \\
\text { R: 5' TCCTTACCTGAACGCCTGTCA 3' }\end{array}$ \\
\hline $18 S$ & $\begin{array}{l}\text { F: 5' TGCATGGCCGTTCTTAGTTG 3' } \\
\text { R: 5' GAGGTCTCGTTCGTTAACGGAAT 3' }\end{array}$ \\
\hline
\end{tabular}

\section{REFERENSES}

Ampomah-Dwamena, C., B.A., Morris, P. Sutherland, B. Veit, and J. L. Yao. 2002. Down-regulation of TM29, a tomato SEPALLATA homolog, causes parthenocarpic fruit development and floral reversion. Plant Physiology, 130: 605-617. 
Barry, C.S., R.P. McQuinn, A.J. Thompson, G.B. Seymour, D. Grierson, and J.J. Giovannoni. 2005. Ethylene insensitivity conferred by the Green-ripe and Never-ripe 2 ripening mutants of tomato. Plant Physiology. 138: 267275.

Bertin N., M. GÉNARD, and S. FISHMAN. 2003A Model for an Early Stage of Tomato Fruit Development: Cell Multiplication and Cessation of the Cell Proliferative Activity.Annual Botany 92 (1): 65-72.

Bindschedler, L.V., E. Wheatley, E. Gay, J. Cole, A. Cottage, and G.P. Bolwell. 2005. Characterization and expression of the pathway from UDP-glucose to UDP-xylose in differentiating tobacco tissue. Plant Molecular Biology, 57: 285-301.

Busi M.V., C. Bustamante, C. D’Angelo, M. Hidalgo-Cuevas, S.B. Boggio, E.M. Valle and E. Zabaleta. 2003. MADS-box genes expressed during tomato seed and fruit development. Plant Molecular Biology 52: 801-815.

Carrari, F., and A.R. Fernie. 2006. Metabolic regulation underlying tomato fruit development. Journal of Experimental Botany, 57: 1883-1897.

Chen, W., J. Kong, T. Lai, K. Manning, C. Wu, Y. Wang. 2015. Tuning LeSPLCNR expression by SlymiR157 affects tomato fruit ripening.Scientific Reports 5: 7852

Clemens Bönisch, C. and S. B. Hake. 2012. Histone $H 2 A$ variants in nucleosomes and chromatin: more or less stable?Nucl. Acids Res., 40 (21): 10719-10741.

Cronquist, A. 1981. An integrated system of classification of flowering plants. Columbia University Press, New York, New York, USA.

De Martino, G., I. Pan, E. Emmanuel, A.A. Levy, V.F. Irish. 2006. Functional analyses of two tomato APETALA3 genes demonstrate diversification in their roles in regulating flowering. PlantCell,18:1833-1845

Dinneny, J.R., D. Weigel, and M.F. Yanofsky. 2005. A genetic framework for fruit patterning in Arabidopsis thaliana. Development, 132: 4687-4696.

Dong Y, T.M. Burch-Smith, Y. Liu, P. Mamillapalli, and S.P. Dinesh-Kumar. 2007. A ligation-independent cloning tobacco rattle virus vector for highthroughput virus-induced gene silencing identifies roles for NbMADS4-1 and -2 in floral development. Plant Physiology, 145: 1161-1170.

Ferrándiz, C. 2002.Regulation of fruit dehiscence in Arabidopsis. Journal of Experimental Botany, 53: 2031-2038.

Ferrándiz C., S.J., Liljegren, and M.F. Yanofsky. 2000.Negative regulation of the SHATTERPROOF genes by FRUITFULL during Arabidopsis fruit development. Science, 289: 436-438.

Frary, A., T.C. Nesbitt, A. Frary, S. Grandillo, E. van der Knaap, B. Cong, J. Liu, et al. 2000. fw2.2: A quantitative trait locus key to the evolution of tomato fruit size. Science, 289: 85-88.

Fu, F.Q., W.H. Mao, K. Shi, Y.H. Zhou, T. Asami and J.Q. Yu. 2008. A role of brassinosteroids in early fruit development in cucumber. Journal of Experimental Botany, 59: 2299-2308. 
Fukuta, N., S. Fujioka, S. Takatsuto, S. Yoshida, Y. Fukuta, and M. Nakayama. 2004. 'Rinrei', a brassinosteroid-deficient dwarf mutant of faba bean (ViciafabaL.). PhysiologiaPlantarum, 121: 506-512.

Fuentes, S., K. Ljung, K. Sorefan, E. Alvey, N. P. Harberd and L. Østergaard. 2012. Fruit growth in Arabidopsisoccurs via DELLA-dependent and DELLAindependent gibberellin responses. Plant Cell,24:3982-96

Gillaspy, G., H. Ben-David, and W. Gruissem. 1993. Fruits: A developmental perspective. Plant Cell, 5: 1439-1451.

Giovannoni, J. 2007. Fruit ripening mutants yield insights into ripening control. Current Opinion in Plant Biology, 10: 283-289.

Gu, Q., C.F Ferrándiz, M.F.Yanofsky, and R. Martienssen. 1998. The FRUITFULL MADS-box gene mediates cell differentiation during Arabidopsis fruit development. Development,125:1509-1517.

Hileman, L.C., J.F. Sundstrom, A. Litt, M. Chen, T. Shumba, and V.F. Irish. 2006. Molecular and phylogenetic analyses of the MADS-box gene family in tomato. Molecular Biology and Evolution,23: 2245-2258.

Jaakola, L., M. Poole, M.O. Jones, T. Kamarainen-Karppinen, J.J. Koskimaki, A. Hohtola, H. Haggman, et al. 2010. A SQUAMOSA MADS Box gene involved in the regulation of anthocyanin accumulation in bilberry fruits. Plant Physiology, 153: 1619-1629.

Jang, S., M.Y. Hong, Y.Y. Chung, and G. An. 1999. Ectopic expression of tobacco MADS genes modulates flowering time and plant architecture. Molecules and Cells, 9: 576-587.

Kevany, B.M., M.G. Taylor, and H.J. Klee. 2008. Fruit-specific suppression of the ethylene receptor LeETR4 results in early-ripening tomato fruit. Plant Biotechnology Journal, 6: 295-330.

Kieliszewski, M., and D.T.A. Lamport. 1994. Extensin: repetitive motifs, functional sites, post-translational codes, and phylogeny. Plant Journal, 5: 157-172.

Klahre, U., T. Noguchi, S. Fujioka, S. Takatsuto, T. Yokota, T. Nomura, S. Yoshida, and N.H. Chua. 1998. The Arabidopsis DIMINUTO/DWARF1 gene encodes a protein involved in steroid synthesis. Plant Cell, 10: 16771690.

Klee, H.J. 2002. Control of ethylene-mediated processes in tomato at the level of receptors. J. of Exp. Bot., 53: 2057-2063

Lee S.W., J. Robb, and R.N. Nazar. 1992. Truncated phenylalanine ammonialyase expression in tomato (Lycopersicum esculentum). Journal of Biological Chemistry, 267: 11824-11830.

Leseberg, C.H., C.L. Eissler, X. Wang, M.A. Johns, M.R. Duvall, and L. Mao. 2008. Interaction study of MADS-domain proteins in tomato. Journal of Experimental Botany,59: 2253-2265.

Nesbitt T. C. and S. D. Tanksley. 2001.fw2.2 Directly Affects the Size of Developing Tomato Fruit, with Secondary Effects on Fruit Number and PhotosynthateDistribution1. Plant Physiology, 127(2): 575-583 
Pabón-Mora, N. and A. Litt. 2011. Comparative anatomical and developmental analysis of dry and fleshy fruits of Solanaceae. American Journal of Botany, 98 (9): 1415-1436.

Pelaz, S., G.S. Ditta, E. Baumann, E. Wisman, and M.F. Yanofsky. 2000. B and $\mathrm{C}$ floral organ identity functions require SEPALLATA MADS-box genes. Nature, 405: 200-203.

Ro, D.K., and C.J. Douglas. 2004. Reconstitution of the entry point of plant phenylpropanoid metabolism in yeast (Saccharomyces cerevisiae). Journal of Biological Chemistry, 279: 2600-2607

Schantz, M., R. Schantz, and G. Houlné, 2001. Fruit-developmental regulation of bell pepperknolle gene (cakn) expression. BiochimicaetBiophysicaActa,1518: 221-225.

Shibuya, K., K.G. Barry, J.A. Ciardi, H.M. Loucas, B.A. Underwood, S. Nourizadeh, J.R. Ecker, et al. 2004. The central role of PhEIN2 in ethylene responses throughout plant development in petunia. Plant Physiology, 136: 2900-2912.

Smykal, P., J. Gennen, S. De Bodt, V. Ranganath, and S. Melzer. 2007. Flowering of strict photoperiodic Nicotiana varieties in non-inductive conditions by transgenic approaches. Plant Molecular Biology, 65: 233-242.

Symons, G.M., C. Davies, Y. Shavrukov, I.B. Dry, J.B. Reid, and M.R. Thomas. 2006. Grapes on steroids. Brassinosteroids are involved in grape berry ripening. Plant Physiology, 140:150-158.

Tanksley, S.D. 2004. The genetic, developmental, and molecular bases of fruit size and shape variation in tomato. Plant Cell,16: S181-S189.

Vardhini, B.V., and S.S.R. Rao. 2002. Acceleration of ripening of tomato pericarp discs by brassinosteroids. Phytochemistry, 61: 843-847.

Wang, L, J. Li, J. Zhao, and C. He. 2015.Evolutionary developmental genetics of fruit morphological variation within the Solanaceae. Frontiers in Plant Science, 6: 248

Xiao, H., C. Radovich, N. Welty, J. Hsu, D. Li, T. Meulia, and E. van der Knaap. 2009. Integration of tomato reproductive developmental landmarks and expression profiles, and the effect of SUN on fruit shape. BMC Plant Biology, 9: 4 


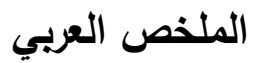 \\ التعبير الجيني ووظيفته في التاثير على مسار نمو الثمار الجافة والغضة في العائلة الباننجانية
}

\author{
عبير محمد محمد 1 و حسام الدين محمد فتحى الوكيل 2,1 \\ 1قسم النبات الزراعي - كلية الزراعة (سابا باشا) - جامعة الاسكندرية \\ 2 البلية البيوتكنولوجي - جامعة العلوم الحديثة - دبي
}

يؤثز مسار نمو الثمار على جودتها وكميتها ـ لذلك فان دراسة نمو الثمارعلى المستوى الجزيئي هوخطوة مهمة

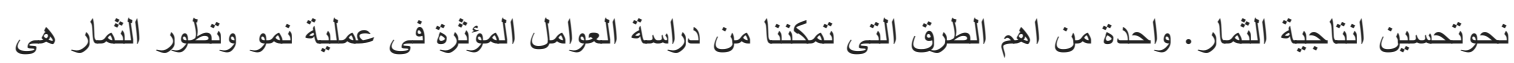

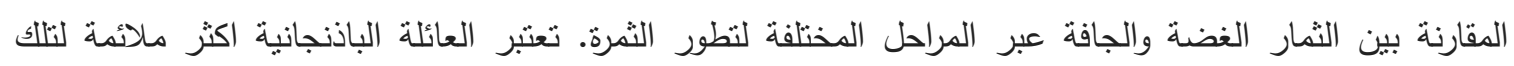

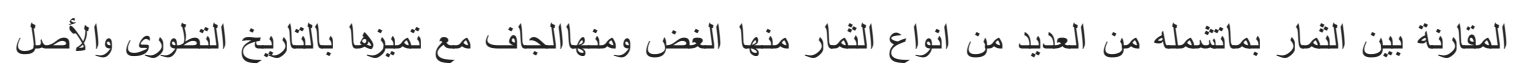

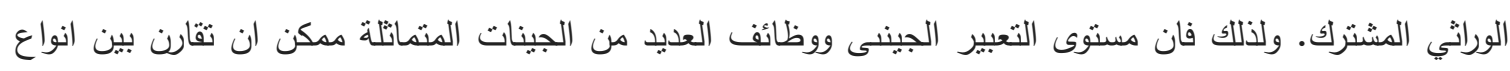

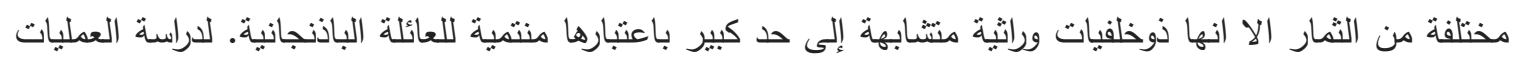

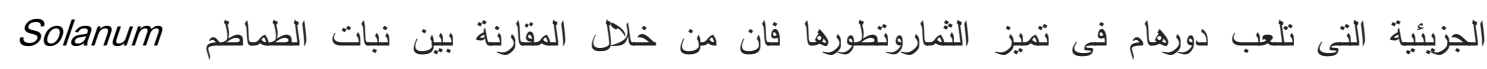
lycopersicum في تثكل الثمار . استخدم تقنيات وRT-PCR وRT-PCR لدراسة التعبير الجينى فى أنسجة مختلفة ومراحل تتموية مختلفة. 